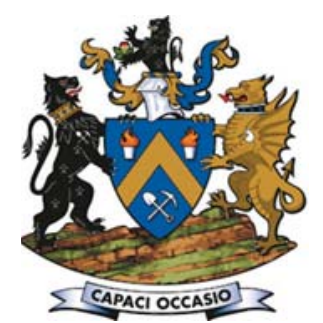

\title{
Statistical analysis of coal mining safety in China with reference to the impact of technology
}

\author{
by C. Chu*, R. Jain ${ }^{\dagger}$, N. Muradian ${ }^{\dagger}$, and G. Zhang*
}

\section{Synopsis}

This paper presents a statistical analysis of coal mining safety which shows a positive relationship between technological innovation and the state of safety in Chinese coal mines. Fatalities per million tons, labour productivity, and fatalities per 10000 exposure hours are the indicators used to analyse the situation of Chinese coal mining safety during the years 2001-2010. A correlation analysis is provided using Statistics Package for Social Science (SPSS). The results show that during this period, there was a positive correlation between technological development, financial investment in safety, and coal mine safety in China. The Huainan Mining Group is taken as an example to illustrate the improvement in coal mine safety due to technological development. Finally, some suggestions are proposed to further improve safety in Chinese coal mines from the perspective of risk assessment, an interdisciplinary approach, and safety culture.

\section{Keywords}

coal mining safety, correlation analysis, labour productivity, technological development. on the data for coal production and safety inputs, the safety level of a country can be divided into a developing stage, stable stage, and transcending stage. At present, China is in the first stage, with a simultaneous growth in coal production and safety inputs. By considering the essential factors causing coal mine accidents, Liang et al. (2011) set up a coal mine accident causation model based on hazard theory to analyse typical coal mine accidents. Focusing on small-scale coal mines, Shi (2013) postulated that China's policy on small coal mines had changed from encouragement to restriction, and ownership had converted from privatization to nationalization in some provinces in the past decades, resulting in improved safety. Liu and Luo (2012) in an analysis of the effect of the psychological factors in coal mine accidents, concluded that accidents in Chinese coal mines were often caused by human factors, such as unsafe behaviour tied to psychological conditions.

This paper presents a more comprehensive statistical analysis to investigate the influence of technical innovation and financial investment on mining safety. Firstly, labour productivity and fatalities per 10000 exposure hours are used to analyse the progress of Chinese coal mine safety from 2001 to 2010 after comparing the fatality rates per million tons produced in Chinese, USA, and Indian coal mines during this period. Secondly, a correlation analysis is conducted through Statistics Package for Social Science (SPSS) to further analyse the impact of technological development and financial investment in
* School of Resources and Geosciences, China University of Mining and Technology, Xuzhou, Jiangsu, China.

$\uparrow$ School of Engineering and Computer Science, University of the Pacific, Stockton, USA.

(C) The Southern African Institute of Mining and Metallurgy, 2016. ISSN 2225-6253. Paper received Apr. 2015; revised paper received Jul. 2015. 


\section{Statistical analysis of coal mining safety in China}

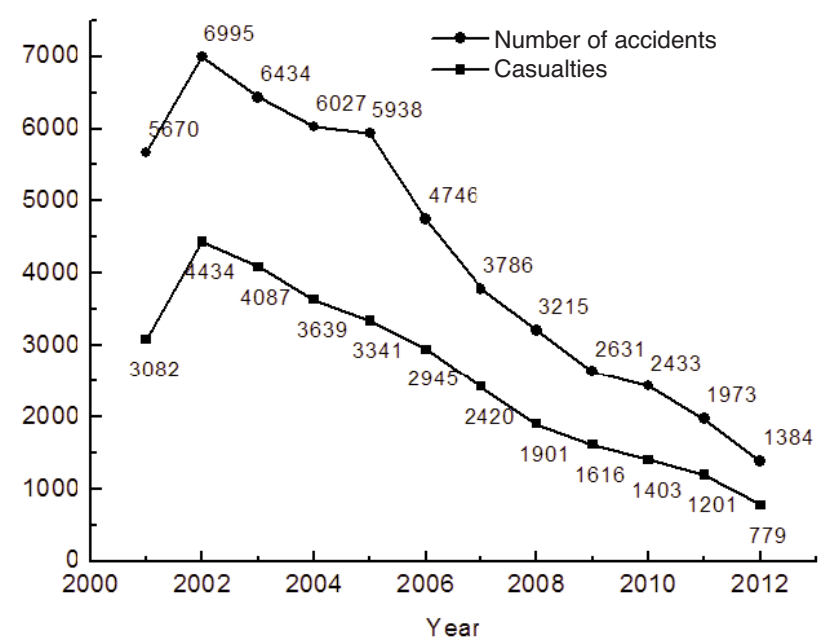

Figure 1-Casualties and number of accidents in Chinese coal mines, 2001-2012

safety on Chinese coal mine safety during the period 20012010. A case study is provided to present the development of coal mine safety due to technological innovation. Finally, some suggestions to improve Chinese coal mine safety are proposed from the perspective of risk assessment, an interdisciplinary approach, and safety culture.

\section{Comparative analysis between China and the global mining community}

China is the world's top producer and consumer of coal, accounting for nearly $50 \%$ of the world's production and consumption. The majority of Chinese coal resources are distributed in the western and northern China, such as Xinjiang and Inner Mongolia, as shown in Figure 2.

China is currently emerging from a period of industrialization and great economic growth, and is in the same position as Britain and the USA many years ago. Chinese coal mine safety is lacking compared with other countries. In 2003, world coal production was 5 billion tons and about 8000 miners died worldwide, with China making up $80.4 \%$ of the total fatalities in coal mine accidents. According to a 2011 report, in China, gas explosions were the most severe type of accident due to the number of fatalities per accident, and collapses were the most frequent type of accident (Wang et al., 2011). Groundwater inrush hazards also caused significant economic losses and casualties (Sui et al., 2011; 2015a). Figure 3 shows the fatality rate per million tons in Chinese coal mines from 2001 to 2010. During this period, the average fatality rate per million tons in China was 2.6, 87 times that of the USA (Figure 4) and 10 times that of India (Figure 5). However, the Chinese death rate declined steadily from 2001, to 0.89 per million tons in 2009, a decrease of $82 \%$. During the same period, the fatality rate per million tons declined by $72 \%$ in India, and by $51 \%$ in the USA.

Labour productivity is commonly used in the coal mining industry as a general indicator of changes in the efficiency of the coal production process. In this paper, labour productivity

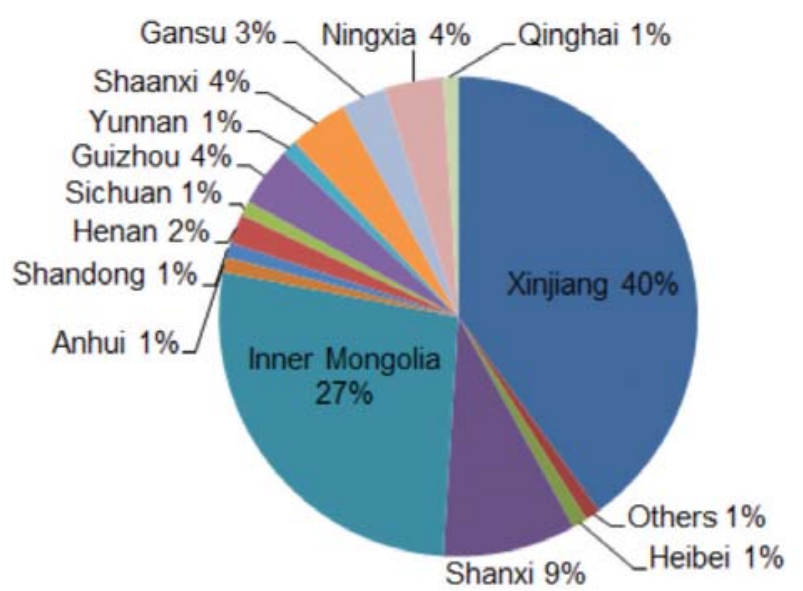

Figure 2-Distribution of coal resources in China

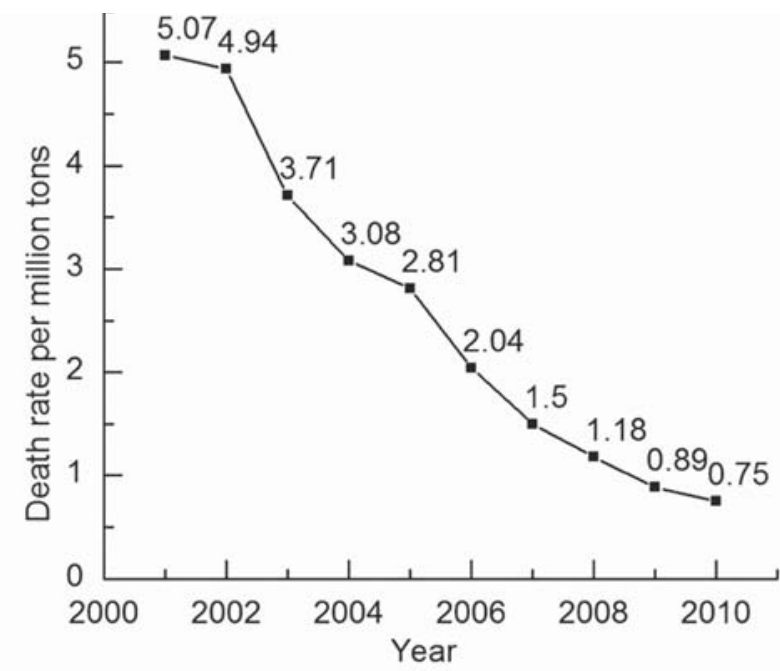

Figure 3-Fatality rate per million tons in Chinese coal mines, 20012010

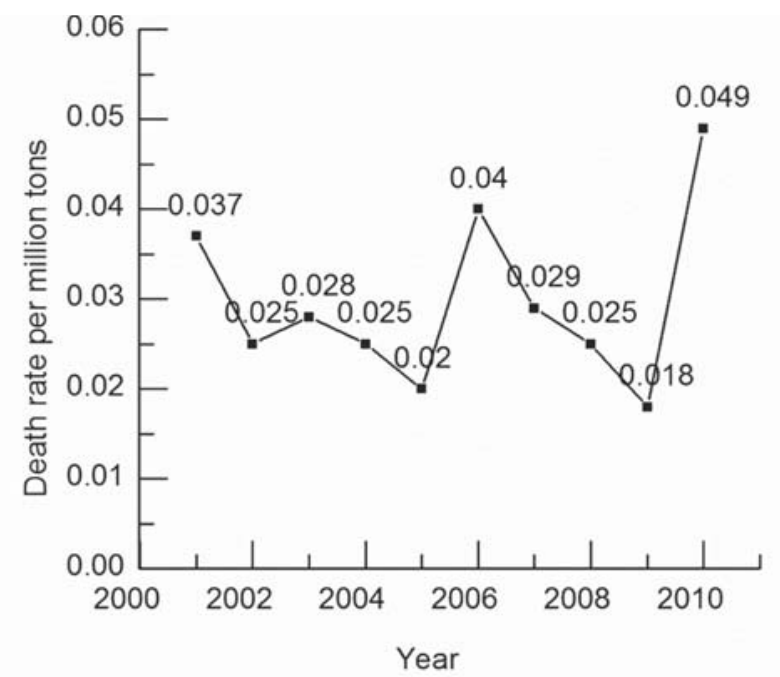

Figure 4-Fatality rate per million tons related to coal mining accidents in the USA 


\section{Statistical analysis of coal mining safety in China}

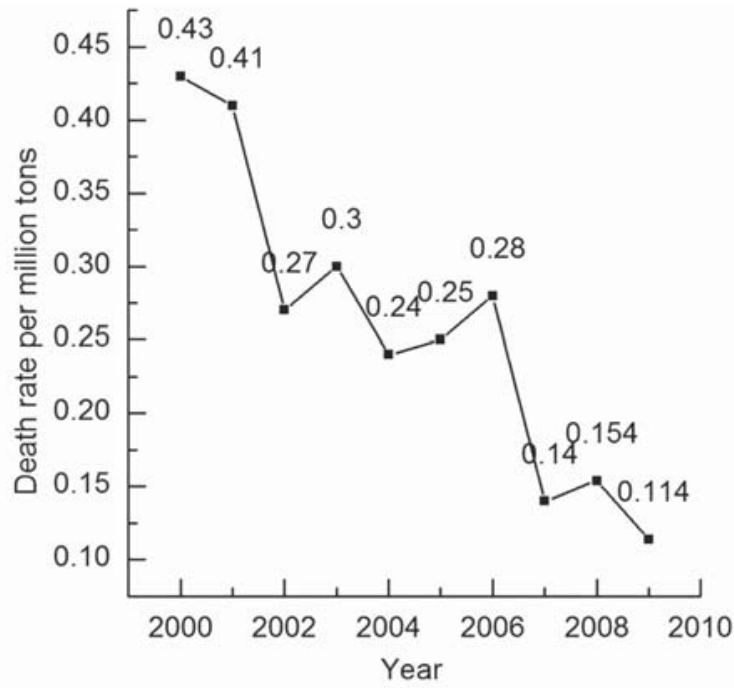

Figure 5-Fatality rate per million tons due to coal mine accidents in India

is measured by total coal production divided by man-hours worked by all employees engaged in production, processing, development, maintenance, repair shop, or yard work at mining operations, including office workers. In each country, working hours are assumed to be 2080 hours per year per worker based on 52 weeks in a year, 5 days a week, and 8 hours a day, excluding vacations and overtime (Sari et al., 2001). New South Wales and Western Australia are used as two examples to present labour productivity in Australia. As shown in Table I, in 2010 the labour productivity in China was approximately one-third that of the UK, one-eleventh that of Australia, and one-fourteenth that of the USA. In the same year, the fatality rate per million tons in China was fifteen times that of the USA, indicating that low labour productivity is correlated with high deaths rates.

Even with low labour productivity, Chinese coal mine safety has increased during of 2001-2010, as illustrated by a decrease in deaths per 10000 exposure hours, shown in Table II. In 2010, the fatality rate per 10000 exposure hours in China was only 1.15 times that in the USA, compared to six times that in the USA in 2002 (Department of Energy and Climate Change, 2013; Mines Safety and Health Administration, 2014; Wikipedia, 2014).

Statistics from 2001 to 2010 (Table III) shows that the Chinese government made an effort to improve coal mine safety through increasing financial investment and improving technology (Chen et al., 2012; Feng and Chen et al., 2013). The physical output of a worker can be assumed to remain constant over the time period considered. Hence, any increase in productivity per person is likely to be due to a change in technology. Thus, the rate of technological progress was represented by labour productivity in tons per person-day.

One of the striking features of this data is that investment in safety increased from a modest 36.2 billion dollars in 2001 to 628.4 billion dollars in 2010 . This investment was accompanied by a decrease in the death rate per million tons from 5.07 in 2001 to 0.75 in 2010 . Additionally, although not presented in Table III, the death rate per million tons decreased even further to 0.25 in 2014, the lowest ever recorded. Over the same time period, the rate of technological progress rose from approximately 1 in 2001 to 2.37 in 2010.

It seems that the decrease in fatalities per million tons has a close relationship with financial investment in safety.

Table I

Labour productivity (tons per exposure hour)

\begin{tabular}{|l|c|c|c|c|c|c|c|c|c|c|}
\hline Year & $\mathbf{2 0 0 1}$ & $\mathbf{2 0 0 2}$ & $\mathbf{2 0 0 3}$ & $\mathbf{2 0 0 4}$ & $\mathbf{2 0 0 5}$ & $\mathbf{2 0 0 6}$ & $\mathbf{2 0 0 7}$ & $\mathbf{2 0 0 8}$ & $\mathbf{2 0 0 9}$ & $\mathbf{2 0 1 0}$ \\
\hline China & 0.20 & 0.21 & 0.25 & 0.28 & 0.31 & 0.32 & 0.34 & 0.37 & 0.38 & 0.42 \\
USA & 7.00 & 7.00 & 7.26 & 7.23 & 6.86 & 6.74 & 6.78 & 6.49 & 5.89 & 6.05 \\
UK & 1.40 & 1.44 & 1.68 & 1.50 & 1.60 & 1.83 & 1.36 & 1.44 & 1.44 & 1.44 \\
New South Wales & - & 6.94 & 7.05 & 7.07 & 6.66 & 6.13 & 6.11 & 5.54 & 5.16 & 4.76 \\
Western Australia & 4.40 & 4.64 & 4.52 & 4.66 & 4.30 & 4.52 & 3.45 & 3.61 & 4.35 \\
\hline
\end{tabular}

Table II

Comparison of fatalities per 10000 exposure hours, China and the USA

\begin{tabular}{|c|c|c|c|c|c|c|c|}
\hline \multirow[t]{2}{*}{ Year } & \multicolumn{3}{|c|}{ China } & \multicolumn{3}{|c|}{ USA } & \multirow{2}{*}{$\begin{array}{l}\text { China / USA } \\
\text { Fatalities per } 10000 \\
\text { exposure hours }\end{array}$} \\
\hline & Casualties & Exposure hours & $\begin{array}{c}\text { Fatalities per } 10000 \\
\text { exposure hours }\end{array}$ & Casualties & Exposure hours & $\begin{array}{c}\text { Fatalities per } 10000 \\
\text { exposure hours }\end{array}$ & \\
\hline 2001 & 5670 & 6889740000 & 0.0082 & 42 & 160343040 & 0.0026 & 3.15 \\
\hline 2002 & 6995 & 6840656160 & 0.0102 & 27 & 156969280 & 0.0017 & 6.00 \\
\hline 2003 & 6434 & 6895276960 & 0.0093 & 30 & 147727840 & 0.0020 & 4.65 \\
\hline 2004 & 6027 & 7102819360 & 0.0085 & 28 & 153737960 & 0.0018 & 4.72 \\
\hline 2005 & 5938 & 7212154560 & 0.0082 & 23 & 164908640 & 0.0014 & 5.86 \\
\hline 2006 & 4746 & 7513760800 & 0.0063 & 47 & 172554720 & 0.0027 & 2.33 \\
\hline 2007 & 3786 & 7499554400 & 0.0050 & 33 & 169058240 & 0.0020 & 2.50 \\
\hline 2008 & 3215 & 7584595200 & 0.0042 & 29 & 180666720 & 0.0016 & 2.63 \\
\hline 2009 & 2631 & 7878037440 & 0.0033 & 18 & 182530400 & 0.0010 & 3.30 \\
\hline 2010 & 2433 & 7783726080 & 0.0031 & 48 & 179285600 & 0.0027 & 1.15 \\
\hline
\end{tabular}




\section{Statistical analysis of coal mining safety in China}

Table III

Statistics of coal industry in China, 2001-2010

\begin{tabular}{|c|c|c|c|c|c|c|c|c|}
\hline Year & $\begin{array}{l}\text { Fatalityrate per } \\
\text { million tons }\end{array}$ & $\begin{array}{l}\text { Coal production } \\
\text { (billion tons) }\end{array}$ & $\begin{array}{l}\text { Coal production } \\
\text { growth rate (\%) }\end{array}$ & $\begin{array}{l}\text { Investments } \\
\text { (billion dollars) }\end{array}$ & $\begin{array}{l}\text { Investment growth } \\
\text { rate (\%) }\end{array}$ & Labour force & $\begin{array}{l}\text { Labour } \\
\text { growth rate }\end{array}$ & $\begin{array}{c}\text { Rate of technological } \\
\text { progress }\end{array}$ \\
\hline 2001 & 5.07 & 1.38 & 6.3 & 36.2 & - & 3312375 & 0.0195 & 1.141 \\
\hline 2002 & 4.94 & 1.46 & 5.8 & 47.7 & 31.7 & 3288777 & -0.0071 & 1.216 \\
\hline 2003 & 3.71 & 1.72 & 17.8 & 69.0 & 44.6 & 3315037 & 0.0080 & 1.421 \\
\hline 2004 & 3.08 & 1.99 & 15.7 & 115.1 & 66.8 & 3414817 & 0.0301 & 1.600 \\
\hline 2005 & 2.81 & 2.21 & 11.1 & 103.9 & -9.6 & 3467382 & 0.0154 & 1.746 \\
\hline 2006 & 2.04 & 2.37 & 7.2 & 126.6 & 21.8 & 3612385 & 0.0418 & 1.797 \\
\hline 2007 & 1.50 & 2.53 & 6.8 & 139.4 & 10.1 & 3605555 & -0.0019 & 1.922 \\
\hline 2008 & 1.18 & 2.80 & 10.7 & 169.1 & 21.3 & 3646440 & 0.0113 & 2.100 \\
\hline 2009 & 0.89 & 2.97 & 6.1 & 206.8 & 22.3 & 3787518 & 0.0384 & 2.148 \\
\hline 2010 & 0.75 & 3.24 & 9.1 & 628.4 & 203.8 & 3742176 & -0.0120 & 2.372 \\
\hline
\end{tabular}

Table IV

Pearson correlation coefficients for the relationship between fatality rate per million tons and contributing parameters

\begin{tabular}{|c|c|c|c|c|c|c|c|c|}
\hline & \multicolumn{2}{|c|}{ Technological progress rate } & \multicolumn{2}{|c|}{ Financial investment } & \multicolumn{2}{|c|}{ Coal production growth rate } & \multicolumn{2}{|c|}{ Labour growth rate } \\
\hline & $R$ & $P$ & $R$ & $P$ & $R$ & $P$ & $R$ & $P$ \\
\hline Fatalities rate per million tons & -0.982 & 0.000 & -0.658 & 0.039 & 0.078 & 0.830 & -0.084 & 0.818 \\
\hline
\end{tabular}

Bold values denote significant correlations for the fatality rate per million tons ( $R$ approaches 1 , significance $<0.05$ )

Meanwhile, with the output per person increasing by about the same degree as the fall in death rate, the decline could also be attributed to increasing mechanization. Further analysis to clarify the influence of technological development and financial investment in safety on Chinese coal mine safety during this period should be conducted.

\section{The impact of technological development and financial investment in safety on Chinese coal mine safety}

\section{Statistical analysis}

Using the data presented in Table III and SPSS, a correlation analysis was developed. The fatality rate per million tons was used as the dependent variable, while technological progress rate, coal production growth rate, financial investment, and labour growth rate were independent variables. With a significance coefficient $(P)$ less than 0.05 , a correlational value $(R)$ approaching -1 or 1 indicates there is a significant negative or positive correlation, respectively, between the death rate per million tons and the independent variable of interest. Table IV shows that the correlation value and significance coefficient between technological development and death rate per million tons are estimated to be -0.982 and 0.000 , respectively. The correlation value of financial investment is -0.658 , while the significance coefficient is 0.039 . The labour growth rate and coal production growth rate have little influence on the fatality rate.

Therefore, there is a positive correlation between technological development, financial investment in safety, and coal mine safety in China from 2001 to 2010. With the development of technology and increasing financial investment in safety, the death rate per million tons decreased dramatically. During this period, technological development had a stronger influence on coal mine safety than financial investment in safety

\section{Case study}

As mentioned above, in the past years, with the rapid development of technology in Chinese coal mines, including improvements in mining technology, drilling technology, and disaster prevention and control technology, coal mine accidents rates decreased dramatically even though coal production increased. The Huainan Mining Group, which is located in a developed economic area of East China, is a good example to present this point. The Huainan Mining Group is an important coal base in China due to its favourable geographical location and high-quality coal resources. Coal production in the Huainan Mining Group increased from 17.74 Mt in 2001 to $71.06 \mathrm{Mt}$ in 2012. However, the coal mines in the Huainan mine area are characterized by complex geological structures, great depths (800-1500 m), high in situ water and gas pressure (greater than $6.2 \mathrm{MPa}$ ), high gas content $\left(12-26 \mathrm{~m}^{3} / \mathrm{t}\right)$, soft coal mass (rigidity coefficient about $0.2-0.8)$, and low permeability $(0.001 \mathrm{mD})$. Gas extraction in such geological conditions remains a problem worldwide (Wang et al., 2012). Historically, the Huainan mine area was known as a 'disaster zone' in the Chinese coal industry due to the frequent gas extraction accidents. From 1980 to 1997 , there were 17 gas extraction accidents in Huainan coal mines, with 392 deaths. Since the year 2002, 


\section{Statistical analysis of coal mining safety in China}

the Huainan Mining Group has begun to strengthen technological innovation in gas control by increasing the input to technological research and development and employing professionals. From 2002 to 2004, financial investment in technology research and development was approximately 0.67 billion dollars. During 2005-2007, the investment in technological innovation relied on a tax of 5.5 dollars per ton of coal sold. The income from this tax has increased to 8.3 dollars per ton since 2008. During 20022010 , the total investment in technological development for gas control was up to 2.3 billion dollars. By the end of 2012, the Huainan Mining Group had employed more than 4000 professionals in the field of gas control, and developed some key technological innovations and patents, such as 'simultaneous mining technology of coal and gas in lowpermeability seam group' in 2009. Due to the efforts devoted to the development of technology, a new method of coal and gas mining by roadway retention and borehole drilling behind the working face has been developed and proved to be successful in the Huainan coal mines (Yuan, 2008). The technological development for gas control resulted in 'zero gas extraction accidents' from 2002 to 2012, and the fatality rate in the Huainan coal mines declined from an average of 4.01 per million tons before 2001 to 0.1 in 2011 .

\section{Recommendations for improvement of safety in Chinese coal mines}

Many scholars have presented suggestions for improving safety in Chinese coal mines, including financial investment, regulations, and risk management. To continue to improve safety, the reader's attention is directed towards the improvement of risk assessment, an interdisciplinary approach, and safety culture.

\section{Risk assessment in coal mines}

Around the globe, legislation regulating the health and safety of mine workers, including requirements for risk assessment, is increasing (Joy, 2004). Risk assessment is the scientific process that characterizes the nature and magnitude of health risks to humans and ecological receptors from chemical contaminants and other stressors that may be present in the environment. Risk assessment can be used to conduct a risk analysis to support decision-making, as well as provide an important basis for finding the right balance between different concerns, such as safety and costs (Mahdevari $e t$ al., 2014).

Figure 6 shows the procedure of risk assessment according to the US Environmental Protection Agency (2014). To assess a risk, health problems caused by the pollutant should be identified, and then the health problems at different levels of exposure and the number of exposed people should be estimated. Finally, the extra risk of health problems in the exposed population should be analysed.

Risk assessment in coal mines is an important step in protecting workers as well as complying with regulations. In China, risk assessment has been introduced at certain coal mines for evaluating the hazards associated with ground instability, groundwater inrush, fire, explosions, and electrical works. Wide application of risk assessment in coal mines is an effective way to improve Chinese coal mine safety in the future.

\section{Development of an interdisciplinary approach}

The lack of coal mine safety has multiple facets in technology, the environment, society, economics, and ecology. Therefore, the development of an interdisciplinary approach, such as safety geology and environmental economics, can promote research into coal mine safety and increase the knowledge needed to make comprehensive decisions.

Safety geology is an especially important field that should be taken into consideration. Complex geological conditions associated with incorrect assessment or interpretation are a major contributing factor to frequent accidents in coal mines. Safety geology focuses on finding solutions to these problems from a geological perspective, using geophysical exploration for investigation and predication and risk assessment for gas explosion and groundwater inrush (Sui, 2013).

Environmental economics is an interdisciplinary study of the relationship between the environment and economics. Traditional economics attaches more importance to commercial activities, ignoring social cost (Coase, 1960). However, when profits are made by exploiting natural resources, the environment will be affected. Environmental issues specific to coal mining operations that should be taken into consideration when decisions are made include environmental pollution, ecological damage, and the depletion of natural resources (Sui et. al., 2015b).

\section{Safety culture}

A culture of safety is a fundamental building block in safety management. Life should be respected and company cultures should promote the concept of being 'people-oriented' rather than 'profit-oriented'. 'Humans are powerless before nature' is a negative perspective that does not promote safety. Employees need to have confidence that humans can live in harmony with nature. A strong safety culture will allow managers to make practical regulations that emphasize a harmonious relationship between humans and nature, and strengthen miners' awareness of coal mine safety.

Training and education of employees and managers plays a vital role in improving coal mine safety and is an important aspect of safety culture. Training and education should be

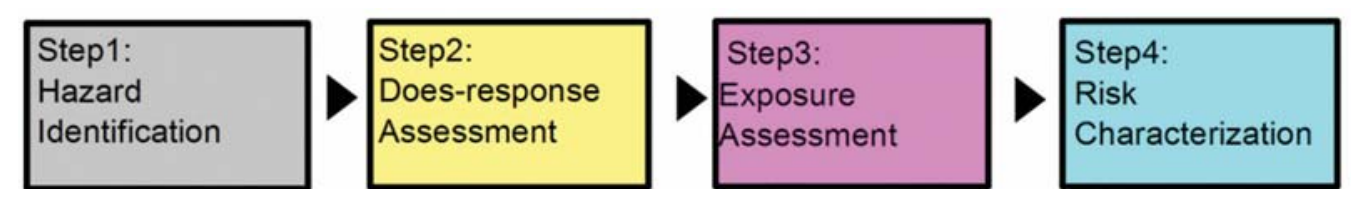

Figure 6-NAS (National Academy of Sciences) risk assessment procedure 


\section{Statistical analysis of coal mining safety in China}

provided to new miners as well as experienced miners. Regular training and education should be required each year or every few months, while a special course should be provided when miners switch jobs or come into contract with new geological conditions. Employees and managers should attend training classes and be tested by written and practical examination. Then, their performances can be made public in a networking system and can be a key factor in their career development.

Psychological education should be more widely implemented in training. Miners' perceptions of safety regulations affect their responses to the regulations, creating situations that may be dangerous. A perception of 'I want to be safe' results in a safer environment than the perception of 'You want me to be safe' (Guo and Wu, 2011). Psychological education can help miners learn how to understand their perceptions and make safe decisions.

\section{Conclusions}

Mining remains a high-risk industry in China, with high accident rates. However, the Chinese fatality rate per million tons of coal produces dropped from 5.07 in 2001 to 0.25 in 2014 through a series of active mitigation measures. In 2010, the fatality rate per 10000 exposure hours in China was only 1.15 times that of the USA. A correlation analysis through Statistics Package for Social Science (SPSS) has shown that technological progress and financial investment in safety had a positive correlation with Chinese coal mine safety during the period 2001-2010. A case study of Huainan Mining Group illustrates that technological development of gas control decreased the gas extraction accident rate dramatically in Huainan coal mines.

Some suggestions have been proposed to further improve safety in Chinese coal mines, including wider application of risk assessment, continued development of interdisciplinary approaches, and the introduction of a strong safety culture.

In the current study, statistical analysis focuses on the impact of technological improvement and financial investment in safety on Chinese coal mine safety. However, many other aspects should be taken into consideration, such as geological conditions, human factors, and safety management. Correlation analysis considering more factors will be conducted in further studies.

\section{Acknowledgements}

This work was supported by the National Natural Science Foundation of China under Grant No. 41172291 and a project funded by the Priority Academic Program Development of Jiangsu Higher Education Institutions (PAPD). The first author was funded by the China Scholarship Council (CSC) during her visit to the USA. Many faculty members and research associates at the School of Engineering and Computer Science, University of the Pacific reviewed the manuscript and provided helpful comments. Their support is gratefully acknowledged. We are also very grateful to the referees for their invaluable and constructive comments.

\section{References}

Chen, H., QI, H., Long, R.Y., and Zhang, M.L. 2012. Research on 10-year tendency of China coal mine accidents and the characteristics of human factors. Safety Science, vol. 50. pp. 745-750.
COASE, R.H. 1960. The problem of social cost. Journal of Law and Economics, vol. 3. pp. 1-44.

Department of Energy and Climate Change. Coal statistics, 2013. http://www.gov.uk [Accessed 20 June 2014].

FEnG, Q. and Chen, H. 2103. The safety-level gap between China and the US in view of the interaction between coal production and safety management. Safety Science, vol. 54. pp. 80-86.

Guo, W.C. and Wu, C. 2011. Comparative study on coal mine safety between China and the US from a safety society perspective. Procedia Engineering, vol. 26. pp. 2003-2011.

Joy, J. 2004. Occupational safety risk management in Australian mining. Occupational Medicine, vol. 54. pp. 311-315.

LiAnG, K.W., Liu, J.K., and WANG, C.X. 2011. The coal mine accident causation model based on the hazard theory. Procedia Engineering, vol. 26. pp. 2199-2205.

Liu, G.Y. and Luo, C.L. 2012. Analysis of the safety psychological factors in the coal mine safety. Procedia Engineering, vol. 45. pp. 253-258.

Mahdevari, S., Shahriar, K., and Esfahanipour, A. 2014. Human health and safety risks management in underground coal mines using fuzzy TOPSIS. Science of the Total Environment, vol. 488-489. pp. 8599.

Mines Safety and Health Administration, Department of Labor, USA. 2014. http://www.msha.gov [Accessed 5 July 2014]

SARI, M., KARPUZ, C., and SELCUK, A.S. 2001. An international comparison of Turkish coal mining industry safety performance. Proceedings of Mine Planning and Equipment Selection, New Delhi, India. vol. 1. pp. 917-922.

SHI, X.P. 2013. China's small coal mine policy in the 2000s: a case study of trusteeship and consolidation. Resources Policy, vol. 38. pp. 598-604.

SuI, W.H. 2013. Safety geology and geological education for mining engineers. Global View of Engineering Geology and the Environment. Wu, F. and Qi, S. (eds.). CRC Press, Boca Raton, FL. pp. 563-567.

Sul, W.H., Zhang, D.Y., CuI Cindy, Z.D., Wu, Z.Y., and Zhao, Q.J. 2015 a. Environmental implications of mitigating overburden failure and subsidences using paste-like backfill mining: a case study. International Journal of Mining, Reclamation, and Environment, vol. 29, no. 6. pp. 521-543. DOI: 10.1080/17480930.2014.969049

Su, W.H., Hang, Y., MA, L.X., Wu, Z.Y., Zhou, Y.J., Long, G.Q., and Wei, L.B. $2015 \mathrm{~b}$. Interactions of overburden failure zones due to multiple-seam mining using longwall caving. Bulletin of Engineering Geology and the Environment, vol. 74, no.3. pp. 1019-1035. DOI: 10.1007/s10064-0140674-9.

Su, W.H., Liu, J.Y., YAng, S.G., ChEn, Z.S., and Hu, Y.S. 2011. Hydrogeological analysis and salvage of a deep coalmine after a groundwater inrush. Environment Earth Sciences, vol. 62. pp. 735-749.

US Environmental Protection Agency. 2014. http://www.epa.gov/ttnatw01/toxsource/paradigm.html [Accessed 10 July 2014].

WAng, F.T., Ren, T., Tu, S.H., Hungerford, F., and Aziz, N. 2012. Implementation of underground longhole directional drilling technology for greenhouse gas mitigation in Chinese coal mines. International Journal of Greenhouse Gas Control, vol. 11. pp. 209-303.

WANG, M.X., Zhang, T., XIE, M.R., Zhang, B., and JiA, M.Q. 2011. Analysis of national coal-mining accident data in China, 2001-2008. Public Health Reports, vol. 126. pp. 270-275.

WiкIPEDIA. 2014. Mining in Western Australia. http://en.wikipedia.org/wiki/Mining_in_Western_Australia\#Coal [Accessed 5 July 2014].

XIE, H.P., Liu, H., and Wu, G. 2013. China's coal industry must follow the path of sustainable production capacity. Official Journal of the World Coal Industry. pp. 11-15.

Yuan, L. 2008. The technique of coal mining and gas extraction by roadway retaining and borehole drilling. Journal of China Coal Society, vol. 33. no. 8. pp. 898-902. 